\title{
Smart Glasses in Health Care: A Patient Trust Perspective
}

\author{
Kai Klinker \\ Technical University Munich \\ kai.klinker@tum.de
}

\author{
Manuel Wiesche \\ Technical University Dortmund \\ manuel.wiesche@tu-dortmund.de
}

\author{
Author's name \\ Technical University Munich \\ krcmar@tum.de
}

\begin{abstract}
Digitization in the health care sector is striving forward. Wearable technologies like smart glasses are being evaluated for providing hands-free and septicsafe access to information systems at the point of care. While smart glasses hold the potential to make service processes more efficient and effective, it is unclear whether patients would opt-in to treatments involving smart glasses. Patients are not active users of smart glasses but are nevertheless affected of outcomes produced by the symbiosis of health care workers and smart glasses. Using an online survey with 437 respondents, we find that it is important to properly explain to patients why smart glasses are being used and to proactively address data privacy concerns. Otherwise, smart glasses can significantly increase risk perceptions, reduce patients' estimates of health care workers' abilities, and decrease patients' willingness to opt-in to medical procedures.
\end{abstract}

\section{Introduction}

Patients value time with their medical personnel. They want to know details about their health status and wish for a warm and trusting relationship with the people who are looking after them. The central role of interaction quality for evoking patient satisfaction has been recognized by numerous studies [1]. High-quality care can only be achieved through a good relationship between patient and caregiver [2]. However, as more and more time in health care is being spent on administrative tasks, there is less time for direct patient care [3]. Health care workers spend large portions of their shifts reading and documenting patient data on computer monitors or paper. As a result, health care personnel frequently experiences a lack of time for direct patient care, which can negatively affect interaction quality and thus patient satisfaction.

Over the last years, various portable devices have been developed for a variety of purposes and applications [4]. Wearable Information- and Communication Technology (ICT) like Augmented Reality (AR) smart glasses are a promising emerging technology that may have the potential to transform health care processes and health management in general. AR smart glasses augment reality with virtual information [5] and could be used to complement or enhance service processes and workflows at the Point of Care (POC) while working hands-free. They could be used to lessen administrative burdens by providing information access at the POC and by documenting procedures while health care workers perform them. Finally, smart glasses could be a vehicle for integrating artificial intelligence engines in daily clinical practice [6].

Some studies suggest that smart glasses can improve processes in domains without direct customer involvement like maintenance and logistics [7]. In the health care sector, smart glasses have been adopted with several useful applications including, hands-free photo and video documentation, telemedicine, Electronic Health Record retrieval and input, rapid diagnostic test analysis, education, and live broadcasting [8-10].

Despite their potential, research on the usage of smart glasses in the health care sector is still at a very early stage and studies taking both, the patient and the health care worker's perspective are scarce [2]. A study by Prochaska et al. found that many patients had concerns about privacy, but very few expressed that it would affect their trust in a doctor [11].

It is easy to imagine that smart glasses might have negative side effects on patient trust and interaction quality. Smart glasses can obscure parts of the health care worker's face or divert attention from the patient, which could negatively impact communication. Furthermore, most smart glasses have outward-facing cameras that are directed at the patient. This might raise privacy concerns on the patient's side, impeding overall acceptance of the technology.

The research question targeted by this work is thus: How does health care workers' use of smart glasses affect trusting beliefs of patients?

In order to answer this question we take an in-depth look at how the use of smart glasses in health care would affect the relationship between medical personnel and patients. Building upon interpersonal 
trust literature, we develop a research model explaining the patient perspective regarding the use of smart glasses in health care settings. We have empirically tested the research model with a survey.

\section{Background}

In this section, we will summarize related work on trust and smart glasses in the health care sector. In general, trust is defined as a latent variable made up of different dimensions [12]. In this work we define trust according to the definition of Mayer, Davis, and Schoorman [13] (page 724): "Trust is the willingness of a party to be vulnerable to the actions of another party based on the expectation that the other will perform a particular action important to the trustor, irrespective of the ability to monitor or control that other party" [13].

\subsection{Trust in person}

One large stream of research in the IS literature has focused on trust between people or between groups [14]. Trustors decide to trust a trustee based on their perceptions of the trustee's abilities, benevolence and integrity [13]. Trust perceptions are also moderated by the trustor's disposition to trust. Whether a trustor decides to be vulnerable to another party or not, depends on his risk perceptions and how much he trusts the trustee [13]. While the main focus of the IS community has been on virtual teams and online markets [14], trust-related research pertaining to professionals in the health care sector also exists.

Patients strive to gain control over their illnesses. Research indicates, that patients perceive contacting medical experts as the most effective means to cope with illness, to reduce uncertainty, and to deal with anxiety [15]. Patients want caregivers to be genuine, not in a hurry, available and willing to talk to them [16]. Patients' willingness to opt-in to a medical procedure depends to a large part on how the procedure is described to them by the medical personnel [17]. There is a general consensus in the nursing field that effective communication with patients is integral to good practice. Trust in the health care provider has been found to correlate positively with adherence to treatment, provider continuity, and perceived effectiveness of care [18]

Nonverbal communication between health care professionals and patients also takes a crucial role in building patients' trust [19]. Nonverbal communication consists of social cues like eye contact, body posture, and facial expressions. Research has shown that consistent eye contact with patients leads to stronger trust, while forward-leaning body posture and smiling did not influence trust [19].

\subsection{Passive trust}

According to Montague and $\mathrm{Xu}$, a passive user is defined as an individual with limited control over the technologies and IT artifacts used in a system [20]. Nevertheless, passive users are directly affected by the results and the outcome of technology use. A passive user can observe the actions and interactions of the active user with the technology. Moreover, the passive user is influenced by outcomes produced by the technology and the active user. A communication of the passive user with the system is only conditionally possible, or is moderated by the active user. Although passive trust has been mentioned in various contexts, little empirical research on this topic can be found [21]. Moreover, passive trust has not been integrated with and delimited by existing trust research.

Very little IS research has focused on the passive user perspective. This finding is supported by Söllner et al., who find that IS research on trust has mainly focused on the trust relationship between the user and the information system itself, largely neglecting that other targets of trust might also drive IS use from a user's point of view [22]. Transferred to the medical context, patients are passive users of medical technologies, while physicians and caregivers are active users.

\subsection{Smart Glasses}

Smart glasses are a new generation of wearable devices that have the potential to transform healthcare processes and healthcare management in general [23, 24]. Their main advantage is that they can be operated hands-free, thus allowing healthcare workers to use both hands for their work while having access to an information system $[9,25,26]$.

It is relevant to passive users to have a rough idea of the active user's actions with a smart glass [27]. This perspective roughly aligns with findings from the technology acceptance literature. While the technology acceptance literature assumes an active user perspective, perceived usefulness has been identified as a key driver for technology acceptance [28]. A study conducted by Weiz et al. indicates that the link between perceived usefulness and actual use is likely to be present in the context of smart glasses [29].

Not much research has been done to understand how smart glasses are being perceived by onlookers [30]. Given the insights into the value of verbal and non-verbal communication in health care for building trust, the question arises how smart glasses would impact communication behaviors between health care workers and patients.

Extant research shows that smart glasses may disturb, disrupt, alter [31], or impair social interaction [32] and thus, may call for a new social etiquette. Smart glass usage is perceived critically, but more positively from a first-person perspective (the user 
herself) than from a second-person perspective [27]. Data privacy concerns are often voiced with regards to smart glasses privacy and can strongly influence users' decision making [33]. Moreover, it is preconceived that smart glasses are always recording [27]. General mistrust in technology manifests itself in behaviors such as laptop users blocking the integrated webcam with Post-its [23]. Hein et al. came to the conclusion that when it comes to smart glasses, people tend to care more about other people's privacy than about their own [23].

\section{Research Method}

Passive trust is inherently linked to both, interpersonal trust and trust in technology. The constructs and models for interpersonal trust are well established.

\subsection{Research Model}

Within our research model, we build upon Mayer's model of interpersonal trust [13]. The research model we developed is depicted in Figure 1. The constructs and arrows drawn in black are adapted from Mayer's model, while hypothesized additions are colored in blue.

As described in the last section, data privacy concerns and perceived usefulness are likely to play a role in the passive trust context. Therefore we incorporated these two factors into our research model and expect them to influence both, trust in the caregiver and opt-in intentions.

A substantial body of literature has shown that trust influences perceptions of perceived usefulness [34]. Thus we hypothesize that patients who trust their caregiver will be more likely to perceive the use of smart glasses as useful (h1).

Furthermore, the technology acceptance model proposes that perceived usefulness predicts behavioral intentions [28]. Behavioral intentions are conceptually very similar to opt-in intentions. Thus we hypothesize that patients who perceive the use of smart glasses in health care to be useful will be more likely to opt-in to medical procedures (h2).

Regarding privacy perceptions, relationships can be inferred from the Privacy-Trust-Behavioral Intention model [35]. It poses that privacy is an antecedent for trust, which in turn predicts behavioral intention. Building upon this model, we expect individuals that hold privacy concerns regarding the use of smart glasses to trust caregivers less (h3).

The second implication of this model is that patients with privacy concerns should also to be less inclined to opt-in to medical procedures involving the use of smart glasses (h4).

\subsection{Study Design}

In order to test our research model and to gain a better understanding of how passive trust works, we used an online survey with two treatments employing a between-subject design.

The online survey was implemented using the limesurvey software. It randomly assigned participants to one of two treatments. One of the treatments was a control treatment without smart glasses, while the other was an experimental manipulation treatment. The main difference between the manipulation and control treatment was the description of a scenario. In the manipulation treatment, smart glasses were used to perform a medical procedure, while there were no smart glasses used in the control treatment.

\subsection{Scenario description}

The text used to describe the scenarios in control and manipulation group were nearly identical. A scenario was described, in which the reader takes a patient's perspective. The patient is lying in a hospital bed and is recovering from an operation. A caregiver enters the room, removes the bandages covering the surgical wound on the left forearm and measures the size of the wound. In total, four pictures of the caregiver performing different actions are provided to make the scenario more vivid.

In the manipulation group, only one short sentence was added that states that smart glasses are currently

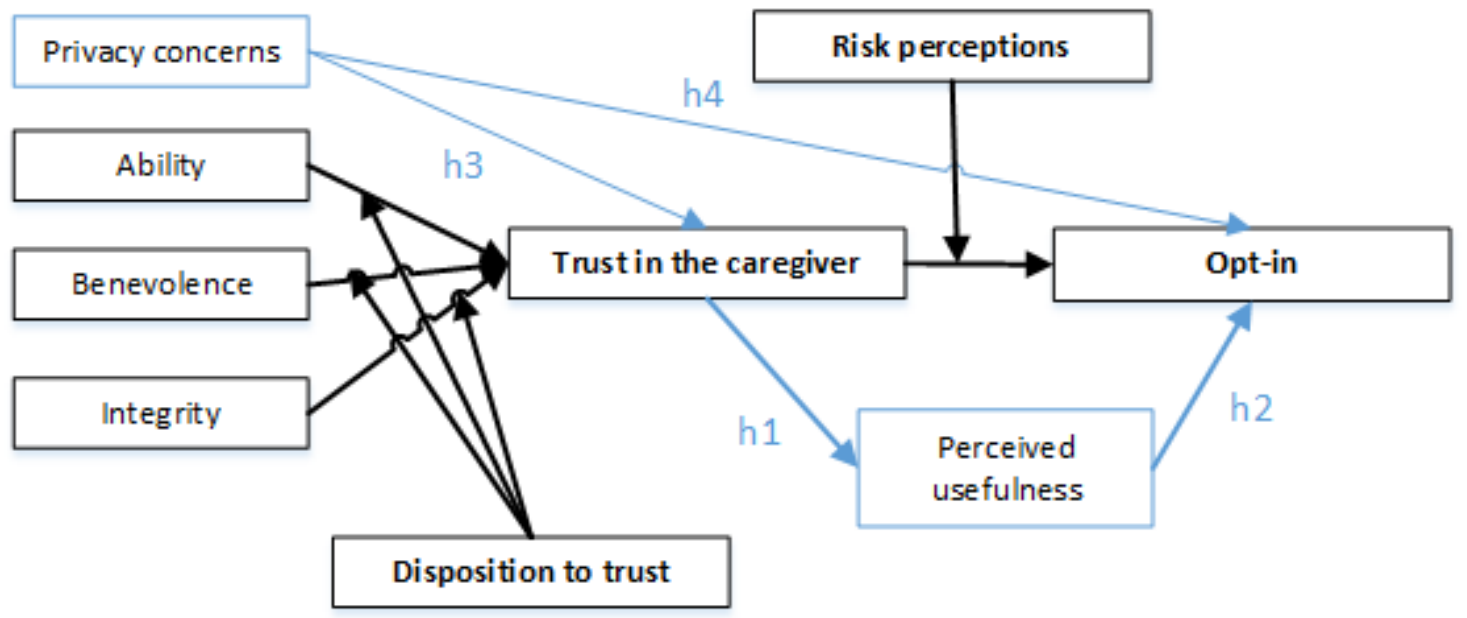

Figure 1: Research model 
being tested by the nursing staff of the hospital. Moreover, on each of the four pictures in the manipulation scenario, the caregiver is wearing smart glasses. The pictures in the control group show the caregiver performing the same actions as in the manipulation scenario but without wearing smart glasses. Figure 2 shows an example of the differences between the pictures employed in the control and manipulation groups.
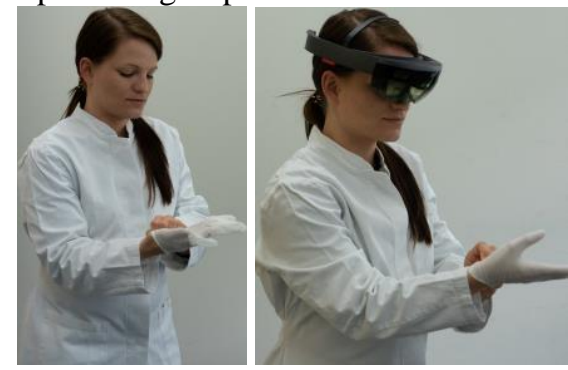

Figure 2: Differences between control and manipulation group. (Left picture: Control group; Right picture: Manipulation group)

\subsection{Data collection}

Participants for the survey were recruited using advertisement on Facebook. We designed an advertisement that asked Facebook users to support one of the author's dissertation project by participating in an online survey about "trust in the health care system".

In order to gather patient perceptions regarding use of smart glasses in health care, we used several constructs that have been developed and validated in prior studies. Wherever necessary, item wording was adapted to the context of this research study. Items for which no German translation could be found in the scientific literature were translated to German using the method described by Brislin et al. [36].

We were not able to find a validated construct for patient opt-in that we deemed appropriate for the context of our study. Therefore we developed items for this construct ourselves. We checked for content validity by testing the items with two researchers trained in scale development. The factor analysis which is presented in the results section of this paper suggests that our construct has good discriminant validity from the other constructs used in this study.

All items and constructs that were used in the online survey are listed in table 1 . The constructs "privacy" and "perceived usefulness" were not used in the control scenario, because their wording is focused on a technology supporting a process. Survey participants were also asked to provide their age, gender and whether they had received surgery before. We also included a control question to assert that survey participants were actually reading the questions.
Table 1: Measurement items

(7-point Likert scales from strongly agree to strongly disagree) German translations can be provided upon request

\begin{tabular}{|c|c|c|}
\hline Constuct & Item & Loading \\
\hline \multirow{3}{*}{$\begin{array}{l}\text { Opt-in } \\
\text { (self-devel- } \\
\text { oped) }\end{array}$} & $\begin{array}{l}\text { I would not have any objections to this } \\
\text { treatment. }\end{array}$ & 0.945 \\
\hline & I would consent to this treatment. & 0.954 \\
\hline & $\begin{array}{l}\text { I would not voice any concerns about this } \\
\text { treatment. }\end{array}$ & 0.887 \\
\hline \multirow{3}{*}{$\begin{array}{l}\text { Disposition } \\
\text { to trust } \\
{[37]}\end{array}$} & I generally trust other people. & 0.862 \\
\hline & I generally count on other people. & 0.881 \\
\hline & I generally have faith in humanity. & 0.815 \\
\hline \multirow{4}{*}{$\begin{array}{l}\text { Ability } \\
{[38]}\end{array}$} & The caregiver is competent. & 0.862 \\
\hline & $\begin{array}{l}\text { The caregiver understands the profession she } \\
\text { works in. }\end{array}$ & 0.904 \\
\hline & $\begin{array}{l}\text { The caregiver knows how to provide excellent } \\
\text { service. }\end{array}$ & 0.841 \\
\hline & The caregiver knows about nursing. & 0.920 \\
\hline \multirow{4}{*}{$\begin{array}{l}\text { Bene- } \\
\text { volence } \\
{[38]}\end{array}$} & $\begin{array}{l}\text { I expect I can count on the caregiver to consider } \\
\text { how its actions affect me. }\end{array}$ & 0.783 \\
\hline & $\begin{array}{l}\text { I expect that the caregiver's intentions are } \\
\text { benevolent. }\end{array}$ & 0.807 \\
\hline & $\begin{array}{l}\text { I expect that the caregiver puts patients' } \\
\text { interests before their own. }\end{array}$ & 0.725 \\
\hline & I expect that the caregiver is well meaning. & 0.833 \\
\hline \multirow[t]{4}{*}{$\begin{array}{l}\text { Integrity } \\
\text { [38] }\end{array}$} & $\begin{array}{l}\text { Promises made by the caregiver are likely to be } \\
\text { reliable. }\end{array}$ & 0.863 \\
\hline & $\begin{array}{l}\text { I expect that the caregiver will keep promises } \\
\text { she makes. }\end{array}$ & 0.813 \\
\hline & I do not doubt the honesty of the caregiver. & 0.726 \\
\hline & $\begin{array}{l}\text { I expect that the advice given by the caregiver is } \\
\text { their best judgment. }\end{array}$ & 0.820 \\
\hline \multirow[t]{4}{*}{ Risk [39] } & $\begin{array}{l}\text { It would be risky to disclose my personal health } \\
\text { information to health care providers. }\end{array}$ & 0.805 \\
\hline & $\begin{array}{l}\text { There would be high potential for loss } \\
\text { associated with disclosing my personal health } \\
\text { information to health care providers. }\end{array}$ & 0.900 \\
\hline & $\begin{array}{l}\text { There would be too much uncertainty } \\
\text { associated with giving my personal health } \\
\text { information to health care providers. }\end{array}$ & 0.969 \\
\hline & $\begin{array}{l}\text { Providing health care providers with my } \\
\text { personal health information would involve } \\
\text { many unexpected problems. }\end{array}$ & 0.933 \\
\hline \multirow[t]{3}{*}{ Trust [40] } & I trust the caregiver to be reliable. & 0.854 \\
\hline & I believe the caregiver to be trustworthy. & 0.922 \\
\hline & I trust the caregiver. & 0.941 \\
\hline \multirow{3}{*}{$\begin{array}{l}\text { Perceived } \\
\text { Usefull- } \\
\text { ness [41] }\end{array}$} & $\begin{array}{l}\text { Using smart glasses enables the caregiver to } \\
\text { complete her daily tasks faster. }\end{array}$ & 0.787 \\
\hline & $\begin{array}{l}\text { Using smart glasses improves the productivity } \\
\text { of the caregiver at her tasks. }\end{array}$ & 0.958 \\
\hline & $\begin{array}{l}\text { Using smart glasses can increase the caregiver's } \\
\text { productivity at work. }\end{array}$ & 0.953 \\
\hline \multirow[t]{3}{*}{$\begin{array}{l}\text { Privacy } \\
{[41]}\end{array}$} & $\begin{array}{l}\text { I feel safe to store private data in the smart } \\
\text { glasses. }\end{array}$ & 0.948 \\
\hline & $\begin{array}{l}\text { The storage of sensitive data on the smart } \\
\text { glasses would worry me. }\end{array}$ & 0.728 \\
\hline & $\begin{array}{l}\text { The use of smart glasses negatively affects my } \\
\text { privacy. }\end{array}$ & 0.850 \\
\hline
\end{tabular}

\subsection{Participants}

Overall, we received 918 responses to our online survey. However, several answers needed to be filtered out, because participants gave incorrect answers to the control question (115 instances) or did not complete the survey (438 instances).

This left us with a total of 437 valid responses to our survey (manipulation: $222(=50.8 \%)$, control 215 (49.2\%)). 69 participants (15.8\%) were male and 368 (84.2\%) were female. The average age was $\mathrm{M}=45.12$ 
years $(\mathrm{SD}=13.93)$. Overall $387(88.6 \%)$ stated that they have received surgery in the past.

The manipulation group $(\mathrm{n}=222)$ was comprised of 42 males (18.9\%) and 180 females (81.1\%). The average age in the manipulation group was $\mathrm{M}=45.2$ years $(\mathrm{SD}=13.87)$. The control group $(\mathrm{n}=215)$ consisted of 27 males $(12.6 \%)$ and 188 females $(87.4 \%)$. The average age was $\mathrm{M}=45.0$ years $(\mathrm{SD}=$ 14.01).

\section{Analysis}

We used IBM SPSS Statistics (25.0) to conduct a descriptive statistical analysis. In addition, SmartPLS 3.0 was used to test the overall structural model and to determine the factor loadings as depicted in table 1 .

\subsection{Reliability analysis}

Focusing on the newly developed construct "Optin", its Cronbach's alpha value is 0.954 , indicating a reasonable internal consistency. In addition, this value did not significantly increase when one of its three items was deleted.

Further, construct reliability was assessed by calculating the composite reliability and average variance extracted for "Opt-in" based on the loadings from Table 1. Composite reliability equals to 0.943 and thereby exceeds the minimum threshold of 0.7 . Average variance extracted results in 0.847 and thereby exceeds the minimum threshold of 0.5 as well. All other constructs employed in this study also exceeded the minimum threshold for Cronbach's alpha.

\subsection{Quantitative Results}

We employed three quantitative approaches to analyze the survey results.

4.2.1. Partial Least Squares SEM. In order to test the hypotheses h1-h4, as well as the path coefficients for the overall model, partial least squares path modeling (PLS-PM) was applied using the data of the manipulation group $(n=222)$.

In order to compute the path coefficients, a consistent PLS algorithm was used to correct for reflective constructs' correlations. Bootstrapping with 2000 samples was used to test whether coefficients such as outer weights, outer loadings and path coefficients are significant by estimating standard errors for the estimates.

The resulting standardized coefficients, as well as their significance levels, are depicted in figure 3. Age and gender were included as independent variables to control for their effects. Regarding the overall model fit the SRMR $(=0.070)$ is lower than the suggested threshold [42]. The adjusted $\mathrm{R}$ square equals 0.657 .

We find hypotheses 1,2 and 4 to be confirmed, while hypothesis 3 was not confirmed. Trust in the caregiver increases perceived usefulness and opt-in intentions, while privacy concerns regarding smart glasses negatively affect opt-in intentions.

Moreover, most aspects of the interpersonal parts of our research model are roughly in line with the results from Mayer et al [13]. Ability, benevolence, and integrity are strong predictors for trust in the caregiver and trust in the caregiver has a positive effect on opt-in intentions. Interestingly, risk perceptions did not have a moderating influence in our study, as described by Mayer et al. [13] and disposition to trust only moderated the relation between integrity and trust.

4.2.2 Mediator and Moderator analysis. Next, we conducted a mediator and moderator analysis for factor combinations involving perceived usefulness and privacy concerns. While we did not find any moderation effects, we found that the relationship between trust in the caregiver and opt-in intention is

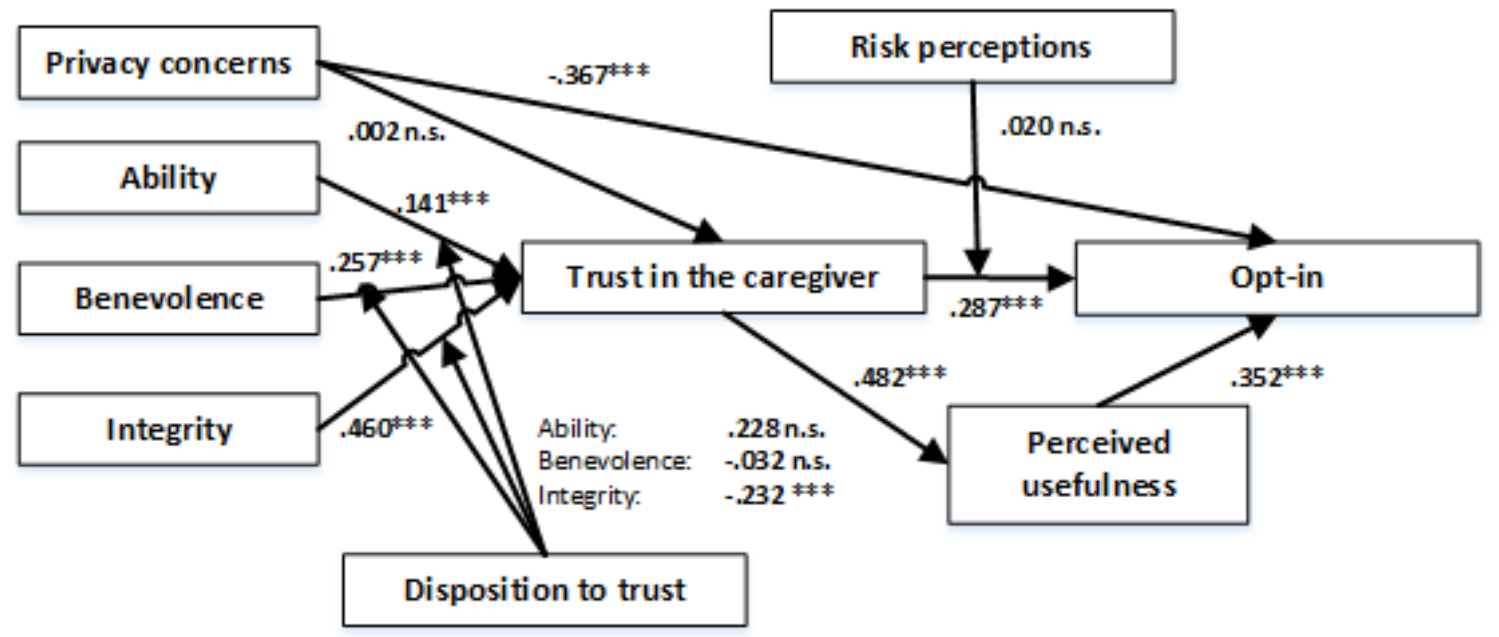

Figure 3: Standardized coefficients

(p-value significance level: *.05, **.01, ***.001) 
partially mediated by perceived usefulness (indirect effect $\mathrm{ab}=.160,95 \%$-CI $[.096, .221])$.

4.2.3 Comparisons between manipulation and control group. To test differences between the two treatments, contrast tests based on the Wilcoxon signed-rank test were used [43]. All significant results $(\mathrm{p}<.05)$ of the contrast tests are reported in the "Comparison"-column of Table 2. In addition, Table 2 also reports means and variances. Data associated with trust, technology acceptance and privacy outcomes were analyzed using an ANOVA test on the two between-subject factors as independent variables: The manipulation treatment (1) shows pictures of a caregiver wearing a smart glass, while the control treatment (2) uses the same scenario description but shows pictures of the caregiver without smart glasses.

Table 2: Survey results (p-value significance level: *.05, **.01,***.001)

\begin{tabular}{|c|c|c|c|c|c|}
\hline \multirow{2}{*}{ Outcomes } & \multicolumn{2}{|c|}{$\begin{array}{c}(1) \\
\text { Manipulation }\end{array}$} & \multicolumn{2}{c|}{$\begin{array}{c}(2) \\
\text { Control }\end{array}$} & \multirow{2}{*}{ Comparison } \\
\cline { 2 - 5 } & M & SD & M & SD & \\
\hline Opt-in & 4.46 & 1.79 & 5.05 & 1.66 & $1<2^{* * * *}$ \\
\hline $\begin{array}{c}\text { Propensity } \\
\text { to trust }\end{array}$ & 3.25 & 1.39 & 3.39 & 1.32 & $\begin{array}{c}\text { No significant } \\
\text { effects }\end{array}$ \\
\hline Ability & 4.44 & 1.27 & 4.71 & 1.40 & $1<2^{*}$ \\
\hline $\begin{array}{c}\text { Bene- } \\
\text { volence }\end{array}$ & 4.67 & 1.20 & 4.86 & 1.20 & $\begin{array}{c}\text { No significant } \\
\text { effects }\end{array}$ \\
\hline Integrity & 4.79 & 1.04 & 4.91 & 1.01 & $\begin{array}{c}\text { No significant } \\
\text { effects }\end{array}$ \\
\hline Risk & 3.91 & 1.60 & 3.38 & 1.45 & $1>2^{* * * *}$ \\
\hline Trust & 4.88 & 1.21 & 4.92 & 1.22 & $\begin{array}{c}\text { No significant } \\
\text { effects }\end{array}$ \\
\hline
\end{tabular}

4.2.4 Effects of age and gender. Within the manipulation group we checked whether age and gender had an effect on any of the measured constructs. Table 3 lists all constructs that significantly correlated with age in our manipulation group. Age was significantly negatively correlated with the disposition to trust humans as well as the benevolence, integrity and overall trust in the caregiver.

Table 3: Influence of age

(Effect sizes are calculated using spearman's rho. P-value significance level: $* .05, * * .01, * * * .001$ )

\begin{tabular}{|c|c|c|c|c|}
\hline & $\begin{array}{c}\text { Disposition } \\
\text { to trust }\end{array}$ & Benevolence & Integrity & $\begin{array}{c}\text { Trust in } \\
\text { caregiver }\end{array}$ \\
\hline $\begin{array}{c}\text { Effect } \\
\text { size }\end{array}$ & $-.23 * * *$ & $-.23 * * *$ & $-.14 *$ & $-.14 *$ \\
\hline
\end{tabular}

All constructs of the manipulation group that significantly differed between male and female participants are listed in Table 4. Overall, females reported higher risk perceptions and privacy concerns, while perceiving smart glasses to be less useful and being less willing to opt-in to medical procedures involving smart glasses than men.
Table 4: Gender differences

(Calculated using Wilcoxon signed-rank test. P-value significance level: *.05,**.01, ***.001)

\begin{tabular}{|c|c|c|c|c|}
\hline & Opt-in & $\begin{array}{c}\text { Perceived } \\
\text { usefulness }\end{array}$ & $\begin{array}{c}\text { Risk } \\
\text { perceptions }\end{array}$ & $\begin{array}{c}\text { Privacy } \\
\text { concerns }\end{array}$ \\
\hline $\begin{array}{c}\text { Effect } \\
\text { size }\end{array}$ & $-.49 * * *$ & $-.25 *$ & $-.31 * *$ & $-.33^{*}$ \\
\hline
\end{tabular}

\subsection{Qualitative Results}

Participants of the survey also had the option to elaborate their opinions in an open comment text field at the end of the survey. We clustered the qualitative comments into categories and will present them in the following. The number in brackets behind each category indicates the number of comments per category.

4.3.1 The scenario presented in the survey (26 comments). Most comments in this category focused on how the actions of the caregiver were perceived. For instance, some people found that the caregiver did not display a lot of empathy. They would have expected the caregiver to ask follow-up questions about the pain the patient was suffering. Moreover, some participants noticed that the caregiver did not disinfect her hands at the beginning of the procedure. Some participants would have preferred the presence of a doctor to check the wound.

4.3.1 Smart glasses (17 comments). The positive comments on the smart glasses focused on the reduction of errors, higher productivity, and suggestions for other use cases in health care. There were also negative comments about smart glasses. Some survey participants found that caregivers wearing smart glasses look inhuman. Especially because it is difficult to see the caregiver's eyes. Some comments suggest that survey participants would find it difficult to build a trusting relationship with a person wearing smart glasses.

4.3.1 Eye contact ( 12 comments). Patients find eye contact important to assess the caregiver's trustworthiness. Some survey participants perceived smart glasses as a communication barrier. Some comments imply that patients perceive the use of smart glasses as a tradeoff between process efficiency and an emphasis on personal contact during care.

4.3.1 Data security (10 comments). Patients voiced concerns about the misuse of their medical data. They would not like their medical insurance to have access to data that was recorded during their hospital stay. There were also positive comments which mentioned that smart glasses might be able to prevent others from seeing confidential information.

\section{Discussion}

Our results have unveiled several insights into the inner workings of passive trust in the health care sector. The empirical results show that perceived 
usefulness and privacy concerns are important factors regarding smart glasses, trust in caregivers and opt-in intentions. As expected, a mixture of interpersonal trust and technological aspects play a role in explaining optin intentions. This conclusion is highlighted by the mediating effect of perceived usefulness on trust in the caregiver and opt-in intentions.

We can quantitatively confirm results reported in other studies regarding gender and smart glasses. Koelle et al found that females are more likely to express negative feelings about the use of smart glasses [27]. In our study, female participants viewed the use of smart glasses significantly more negatively than male participants in some dimensions. Females reported significantly higher risk perceptions and privacy concerns regarding the use of smart glasses in the presented scenario than the male participants. Furthermore, females perceived the smart glasses to be less useful and were less willing to opt-in to procedures involving smart glasses than men.

Interestingly our findings regarding age differ with the results reported by other studies in which older patients are generally more inclined to trust [19]. In our study, age was negatively correlated with the disposition to trust and trust in the caregiver, which was presented in the scenario. Moreover, older participants rated the benevolence and integrity significantly lower than younger participants. Interestingly, none of these factors are technologyrelated. Instead, they are all clustered on an interpersonal level.

When reflecting upon these results one should keep in mind that we used Facebook as a recruiting tool. Thus the oldest participant in our study was 74 years old, and our sample does not represent the age group of 70 and older. Next, this study took place in the health care context. In the comments section of our survey, we received many individual case descriptions of instances in which participants experienced something that made them loose trust in the health care system. It is possible that older patients have more experience with the health care system and are thus more likely to have experienced something negative.

\subsection{Practical implications}

We purposefully did not provide a detailed explanation of how smart glasses work to the participants of the study. We did this in order to maximize the consistency of our study by keeping it as similar as possible to the control scenario. Moreover, Angst et al. have already shown that patients' willingness to opt-in to a medical procedure depends to a large part on how the procedure is described to them by the medical personnel [17]. The focus of our study was therefore to gather insights into patients' initial perceptions of smart glasses.
Our results show that privacy concerns regarding smart glasses should be taken seriously. When using smart glasses in a professional environment like health care, efforts should be undertaken to increase the perceived usefulness of passive users and to decrease privacy concerns. We recommend providing informational material on what data is being gathered and why the smart glasses are of value. For instance, videos that describe use case scenarios and show the caregiver's perspective using smart glasses could be helpful. As females report higher levels of privacy concerns, it might be a good idea to develop information material that is appealing to them.

\subsection{Theoretical contributions}

We contribute to theory by conducting exploratory work on passive trust. To the best of our knowledge, only very little research has been conducted on this topic. We think that research in this field is needed, as technology and particularly artificial intelligence are becoming more prevalent in our lives. Scenarios in which individuals are dependent on outcomes produced by a symbiosis of humans and machines will occur more frequently.

The constructs that drive passive trust are still elusive. While several parts of the interpersonal trust literature can be reused for the passive trust context, new constructs need to be developed to account for the technological influences. In our research, we make a first step towards this end by developing an opt-in construct. The reliability characteristics of the newly developed construct are good and it can be reused for passive trust research in other contexts. Moreover, we extend the body of research on passive trust by applying well-established constructs from the IS trust literature to context of passive trust.

Furthermore, we contribute to interpersonal and technological trust research. We extend the interpersonal trust model of Mayer [13] to the context of passive trust and identify constructs that help to model technology perceptions. The empirical results of our study suggest that our research model is able to explain how trust perceptions and opt-in intentions emerge and can thus serve as a conceptual basis for further investigation of passive trust. More specifically, we show that perceived usefulness and privacy concerns are important technological factors for passive trust.

Finally, in the following, we will outline an agenda for future research that can help fellow researchers to advance the theoretical knowledge of passive trust.

\subsection{Agenda for future research}

Our study has several limitations. Firstly, we have a very unequal gender representation in our sample. 84\% of this study's participants were female. Thus, despite being statistically significant, the results pertaining to 
gender should be regarded with caution and be treated as preliminary results. We hope that future research will be able to shed more light on gender differences by conducting more empirical studies on the use of smart glasses.

Interestingly, privacy concerns regarding smart glasses did not have a negative effect on trust in the caregiver. One explanation for this might be that patients do not think that medical personnel would be inclined to misuse their data. Qualitative research with patients could shed more light on this finding.

While we were able to show that privacy concerns and perceived usefulness are important factors in the context of passive trust, it is quite likely that we have missed other important factors. Several comments suggest that the empathy displayed by the caregiver could be relevant. This would also be in line with prior findings in the medical literature that highlight the role of communication in health care [2]. Furthermore, as disposition to trust did not have the moderating effect that it has in other contexts, further research is needed. Especially our results pertaining to age suggest that a construct regarding overall trust in the healthcare system should be tested in future questionnaires. Testing constructs like trusting stance and propensity to trust which are related to disposition could be a good starting point for this endeavor.

Similar to disposition to trust, risk perceptions did not have the moderating effect we assumed they would. One aspect that could be interesting for future research is to look into how the severity of an illness affects passive trust and opt-in intentions. It is quite possible that opt-in to medical procedures is higher when a patient has a life-threatening disease than when the patient only has a minor illness. Severity is conceptually different to the construct of risk perceptions we used in this study, as it would focus on the health state of the patient instead of risk concerns regarding the use of smart glasses.

The caregiver's abilities were rated significantly worse in the manipulation scenario, than in the control scenario. This is somewhat surprising because in theory the smart glasses should enhance the caregiver's capabilities and improve the capability to provide professional care. It is possible that patients have a specific picture in mind when it comes to judging a caregiver's capabilities. Maybe patients consider empathic treatment and good communication with the patient to be central to the caregiver's job and perceive smart glasses as a barrier to achieving this goal. Future research should take a more in-depth look at this phenomenon. One way to approach this could be to investigate the patient's perceptions of a caregiver's empathy and to evaluate whether empathy correlates with ability perceptions. Another approach could be to compare whether patients deem it more appropriate if doctors use smart glasses than if caregivers do.

This study focused on the use of smart glasses in the health care sector. However, the notion of passive trust is much broader. In order to be able to make generalizations about passive trust in different contexts and technologies, further research is needed. We encourage fellow researchers to conduct empirical research on use cases in other domains and to compare the results to ours.

\section{Conclusion}

In this research, we have investigated how the use of smart glasses in the health care sector is perceived by patients. Patients are not active users of the smart glasses but are dependent on outcomes produced by caregivers using this technology. Thus both interpersonal and technological aspects play a role in this context.

Building upon interpersonal trust literature we have developed a research model and have tested it empirically using an online survey. As predicted by the interpersonal trust model, the results confirm that ability, benevolence, and integrity predict trust in the caregiver and opt-in intentions to medical procedures. However, risk perceptions and disposition to trust did not have their theorized moderating effects.

Furthermore, we identify patients' perceived usefulness and privacy concerns as relevant factors for modeling technological aspects of smart glasses. Both constructs had strong correlations with trust in caregivers and opt-in intentions.

Age was significantly negatively correlated with several interpersonal constructs. This implies that older people have less trust in caregivers. Female participants had significantly higher risk and privacy concerns than males and were less willing to opt-in to medical procedures involving smart glasses.

Future research on the passive user perspective is needed. The results of our research suggest that several other factors like perceived empathy or severity of the patient's illness could be relevant constructs in the context of passive trust.

\section{Acknowledgements}

This research and development project is / was funded by the German Federal Ministry of Education and Research (BMBF) within the Program "Innovations for Tomorrow's Production, Services, and Work" (02K14A080) and managed by the Project Management Agency Karlsruhe (PTKA). The author is responsible for the contents of this publication. We would especially like to thank Marcus Bräuchle for supporting our research. 
[11] M. T. Prochaska, V. G. Press, D. O. Meltzer, and V. M. Arora, "Patient Perceptions of Wearable Face-Mounted Computing Technology and the Effect on the DoctorPatient Relationship," Applied clinical informatics, vol. 7, no. 04, pp. 946953, 2016.

[12] M. Bühner, Einführung in die Test-und Fragebogenkonstruktion, 3 ed. München, Deutschland: Pearson Education Deutschland GmbH, 2011.

[13] R. C. Mayer, J. H. Davis, and F. D. Schoorman, "An integrative model of organizational trust," Academy of management review, vol. 20, no. 3, pp. 709734, 1995.

[14] M. Söllner, I. Benbasat, D. Gefen, J. M. Leimeister, and P. A. Pavlou, "Trust : An MIS Quarterly Research Curation Focus of the Research Curation," Misq, no. October, pp. 1-9, 2016.

[4] N. Sultan, "Reflective thoughts on the potential and challenges of wearable technology for healthcare provision and medical education," International Journal of Information Management, vol. 35, no. 5, pp. 521-526, 2015.

[5] R. Azuma, "A survey of augmented reality," Presence: Teleoperators and Virtual Environments, vol. 6, no. 4, pp. 355-385, 1997.

[6] N. Wrzesińska, "The use of smart glasses in healthcare-review," MEDtube Science, p. 31, 2015.

[7] C. Niemöller, D. Metzger, and O. Thomas, "Design and Evaluation of a Smart-Glassesbased Service Support System," 13. International Conference on Wirtschaftsinformatik (WI), no. 2017, pp. 106-120, 2017.

[8] S. Mitrasinovic et al., "Clinical and surgical applications of smart glasses," Technology and Health Care, vol. 23, no. 4, pp. 381401, 2015.

[9] K. Klinker et al., "Structure for innovations: A use case taxonomy for smart glasses in service processes," Multikonferenz Wirtschaftsinformatik (MKWI 2018), pp. 1599-1610, 2018.

[10] V. Huck-Fries, F. Wiegand, K. Klinker, M. Wiesche, and H. Krcmar, "Datenbrillen in der Wartung: Evaluation verschiedener Eingabemodalitäten bei Servicetechnikern," in Informatik 2017, 2017.

V. C. Sheer and R. J. Cline, "Testing a model of perceived information adequacy and uncertainty reduction in physician-patient interactions," 1995.

[16] M. Shattell, "Nurse-patient interaction: a review of the literature," Journal of clinical nursing, vol. 13, no. 6, pp. 714-722, 2004.

[17] C. M. Angst and R. Agarwal, "Adoption of electronic health records in the presence of privacy concerns: The elaboration likelihood model and individual persuasion," MIS quarterly, vol. 33, no. 2, pp. 339-370, 2009.

[18] K. Shea and J. A. Effken, "Enhancing patients' trust in the virtual home healthcare nurse," CIN: Computers, Informatics, Nursing, vol. 26, no. 3, pp. 135-141, 2008.

[19] M. A. Hillen et al., "All eyes on the patient: the influence of oncologists' nonverbal communication on breast cancer patients' trust," Breast cancer research and treatment, vol. 153, no. 1, pp. 161-171, 2015.

[20] J. Xu and E. Montague, "Psychophysiology of the passive user: Exploring the effect of technological conditions and personality traits," International Journal of Industrial Ergonomics, vol. 42, no. 5, pp. 505-512, 2012/09/01/ 2012.

[21] K. Klinker, M. Wiesche, and H. Krcmar, "Conceptualizing passive trust: the case of smart glasses in healthcare," in European Conference on Information Systems, 2019.

[22] M. Söllner, A. Hoffmann, and J. M. Leimeister, "Why different trust 
relationships matter for information systems users," European Journal of Information Systems, vol. 25, no. 3, pp. 274-287, 2016.

[23] D. W. Hein, J. L. Jodoin, P. A. Rauschnabel, and B. S. Ivens, "Are wearables good or bad for society?: An exploration of societal benefits, risks, and consequences of augmented reality smart glasses," in Mobile Technologies and Augmented Reality in Open Education: IGI Global, 2017, pp. 1-25.

[24] L. Przybilla, K. Klinker, M. Wiesche, and H. Krcmar, "A Human-Centric Approach to Digital Innovation Projects in Health Care: Learnings from Applying Design Thinking," in PACIS, 2018, p. 226.

[25] H. Wüller, J. Behrens, K. Klinker, M. Wiesche, H. Krcmar, and H. Remmers, "Smart Glasses in Nursing-Situation Change and Further Usages Exemplified on a Wound Care Application," in GMDS, 2018, pp. 191-195.

[26] K. Klinker, M. Wiesche, and H. Krcmar, "Digital Transformation in Health Care: Augmented Reality for Hands-Free Service Innovation," Information Systems Frontiers, pp. 1-13, 2019.

[27] M. Koelle, M. Kranz, and A. Möller, "Don't look at me that way!: Understanding User Attitudes Towards Data Glasses Usage," in Proceedings of the 17th international conference on human-computer interaction with mobile devices and services, 2015: ACM, pp. 362-372.

[28] F. D. Davis, "Perceived usefulness, perceived ease of use, and user acceptance of information technology," MIS quarterly, pp. 319-340, 1989.

[29] D. Weiz, G. Anand, and C.-P. H. Ernst, "The influence of subjective norm on the usage of smartglasses," in The drivers of wearable device usage: Springer, 2016, pp. $1-11$.

[30] M. Kalantari, "Augmented Reality and Virtual Reality," no. November 2017, 2018.

[31] B. Due, "Challenges with Google Glass in social interaction," in $4 T H$ PARTICIPATORY INNOVATION CONFERENCE 2015, 2015, p. 440.

[32] T. Jacquemard, P. Novitzky, F. O’Brolcháin, A. F. Smeaton, and B. Gordijn, "Challenges and opportunities of lifelog technologies: A literature review and critical analysis," Science and engineering ethics, vol. 20, no. 2, pp. 379-409, 2014.
[33] P. A. Rauschnabel, J. He, and Y. K. Ro, "Antecedents to the adoption of augmented reality smart glasses: A closer look at privacy risks," Journal of Business Research, vol. 92, no. April 2016, pp. 374384, 2018.

[34] D. Gefen, E. Karahanna, and D. W. Straub, "Trust and TAM in online shopping: an integrated model," MIS quarterly, vol. 27, no. 1, pp. 51-90, 2003.

[35] C. Liu, J. T. Marchewka, J. Lu, and C.-S. $\mathrm{Yu}$, "Beyond concern-a privacy-trustbehavioral intention model of electronic commerce," Information \& Management, vol. 42, no. 2, pp. 289-304, 2005.

[36] R. W. Brislin, "Back-translation for crosscultural research," Journal of cross-cultural psychology, vol. 1, no. 3, pp. 185-216, 1970.

[37] H. Liang, K. Laosethakul, S. J. Lloyd, and Y. Xue, "Information systems and health care-I: trust, uncertainty, and online prescription filling," Communications of the Association for Information Systems, vol. 15, no. 1, p. 2, 2005.

[38] D. Gefen and D. W. Straub, "Consumer trust in B2C e-Commerce and the importance of social presence: experiments in e-Products and e-Services," Omega, vol. 32, no. 6, pp. 407-424, 2004.

[39] G. Fox and R. Connolly, "Mobile health technology adoption across generations: Narrowing the digital divide," Information Systems Journal, vol. 28, no. 6, pp. 9951019, 2018.

[40] S. C. Srivastava and S. Chandra, "Social presence in virtual world collaboration: An uncertainty reduction perspective using a mixed methods approach," MIS Quarterly, vol. 42, no. 3, pp. 779-803, 2018.

[41] D. B. Wilhelm, Nutzerakzeptanz von webbasierten Anwendungen: Modell zur Akzeptanzmessung und Identifikation von Verbesserungspotenzialen. Springer-Verlag, 2013.

[42] J. Benitez, J. Henseler, A. Castillo, and F. Schuberth, "How to perform and report an impactful analysis using partial least squares: Guidelines for confirmatory and explanatory IS research," Information \& Management, 2019.

[43] F. Wilcoxon, "Individual comparisons of grouped data by ranking methods," Journal of economic entomology, vol. 39, no. 6, pp. 269-269, 1946. 